\title{
Peningkatan Kinerja Inventory Planning pada Mitra 10 Melalui Pelatihan Demand Planning Management
}

\author{
Yuli Evitha ${ }^{a, 1, *}$, Cundo Harimurti ${ }^{b, 2}$, I Nyoman Purnaya ${ }^{b, 3}$, Resista Vikaliana ${ }^{b, 4}$ \\ ${ }^{a}$ Manajemen Logistik, Fakultas Ilmu Sosial dan Manajemen Stiami, Institut Ilmu Sosial dan Manajemen Stiami \\ ${ }^{\mathrm{b}}$ Manajemen Logistik, Fakultas Ilmu Sosial dan Manajemen Stiami, Institut Ilmu Sosial dan Manajemen Stiami \\ 1 resista@stiami.ac.id* \\ * corresponding author
}

\section{ARTICLE INFO}

\section{Article history}

Received

Revised

Accepted

Keywords

Demand Planning

Management,

Training,

PT Mitra 10

\begin{abstract}
Companies such as PT Mitra 10, in a competitive business world, need the role of the right business strategy, especially in supply-demand. Therefore, to avoid unbalanced supply-demand conditions, it is necessary to do supplydemand planning which always starts from demand planning. Planning that prioritizes demand in determining the amount of supply will produce a more balanced supply-demand condition than providing supply without prioritizing demand.
\end{abstract}

Partner Company 10 requires superior HR competencies, to implement demand planning in its business processes. This competency is needed so that every HR is reliable in carrying out demand planning. Training is one of the ways expected to improve HR competencies.

Demand Planning Management training is considered capable of being a solution to partner problems. The training was also considered capable of meeting the needs of Partner 10, with the aim of providing participants with techniques and methods for effective and integrated logistics management, which included purchasing, warehousing, inventory control and distribution of goods. This training is expected to improve the performance of PT Mitra 10.

\section{A. PENDAHULUAN}

\section{Analisis Situasi}

Dalam dunia bisnis saat ini, persaingan tak terelakkan. Perusahaan memerlukan inventory planning untuk demand management dan sales forecasting yang merupakan sebuah manufacturing planning \& control system dalam suatu perusahaan.

Untuk produk, ketidakseimbangan perencanaan supply-demand dapat dengan mudah mengubah harga di pasar. Dalam kondisi di mana demand lebih besar daripada supply, maka produk akan menjadi langka di pasar. Sehingga muncul kepanikan jika produk akan habis (out of stock). Dalam kondisi seperti inilah akan muncul ketidakstabilan harga.

Untuk produk jadi, ketidakseimbangan perencanaan supply-demand dapat mengakibatkan kerugian dan penurunan pendapatan bagi perusahaan. Dalam kondisi demand lebih besar daripada supply, maka dapat terjadi kondisi out of stock (OOS) sehingga kerugian muncul dari hilangnya kesempatan untuk menjual produk. Sebaliknya, dalam kondisi supply lebih besar daripada demand, perusahaan juga mengalami kerugian dari biaya inventory yang besar sehingga tidak bisa dijual. Untuk itu, perencanaan supply-demand yang baik akan meningkatkan keuntungan perusahaan dari efisiensi biaya yang seharusnya tidak menjadi beban perusahaan.

Ada dua entitas penting yang berperan dalam perencanaan supply-demand, yaitu supplier (produsen) dan seller (penjual). Aliran produk akan mengalir dari supplier menuju ke seller. Namun, untuk aliran proses perencanaan supply-demand, data akan mengalir terbalik dari seller menuju ke supplier.

Banyak perusahaan beranggapan bahwa perencanaan supply-demand selalu dimulai dari supply. Hal ini mengakibatkan seller hanya menjual produk sesuai dengan kemampuan supplier menyediakan supply produk. Dalam kondisi demand lebih besar daripada supply, maka akan terjadi kondisi OOS. Namun dalam kondisi supply lebih besar daripada demand, maka produk akan menumpuk menantikan peningkatan demand 
pembeli. Jika perencanaan dimulai dari supply, maka informasi demand akan muncul setelah terjadi kejadian seperti kurangnya supply atau menumpuknya supply. Tidak terdapat kemampuan perusahaan untuk memprediksi kondisi keseimbangan supply-demand ke depan. (Ramanda \& Vikaliana, 2019)

Walaupun perencanaan supply-demand yang dimulai dari demand memberikan banyak keuntungan, namun tidak mudah untuk mendapatkan angka demand. Untuk mendapatkan angka demand, perusahaan harus melakukan forecasting atau peramalan. Peramalan (forecasting) yaitu sebuah seni dan ilmu yang memprediksi peristiwa masa depan (Haizer \& Render, 2016). Peramalan memerlukan pengambilan suatu data historis dan memproyeksikannya ke masa depan. Di sinilah tantangannya bagaimana perusahaan untuk mendapatkan data forecasting demand yang akurat. Ada beberapa cara untuk melakukan forecasting demand yang akurat. Cara ini dibahas lebih detail dalam ilmu manajemen yang disebut Demand Management.

Menurut Hasibuan (2011) manajemen adalah ilmu dan seni mengatur proses pemanfaatan sumber daya manusia dan sumber-sumbber lainnya secara efektif dan efisien untuk mencapai suatu tujuan tertentu. Manajemen adalah suatu fungsi untuk mengetahui semua kebutuhan produk atau jasa dari pelanggan.

Proses demand management termasuk di dalamnya melakukan aktivitas apa saja yang dibutuhkan agar suatu perusahaan dapat berjalan dengan baik, lebih efektif dan lebih efisien. Untuk proses tingkat penawaran akan dipengaruhi oleh beberapa faktor, antara lain (Kotler, 2010): 1. Biaya produksi dan teknologi yang digunakan 2. Tujuan dari suatu Perusahaan 3. Pajak 4. Ketersediaan dan harga barang pengganti atau pelengkap 5. Prediksi atau perkiraan harga di masa depan. Sedangkan pada tingkat permintaan akan dipengaruhi oleh beberapa faktor, antara lain oleh: 1. Perilaku atau selera konsumen 2. Ketersediaan dan harga barang sejenis pengganti dan pelengkap 3. Pendapatan atau penghasilan konsumen 4. Perkiraan harga di masa depan 5. Banyaknya atau intensitas kebutuhan konsumen.

Demand Management terdiri atas Demand Planning serta Demand Control dan Execution. Demand Planning sendiri di dalamnya ada forecasting, hubungan pelanggan dengan rencana kebutuhannya , perencanaan produk atau jasa baru dan inventorinya, strategi kapasitas. Kualitas informasi hasil rencana kebutuhan produk dan jasa yang paling utama dimana dalam prosesnya harus dapat didefinisikan dan dapat disanggupi dalam satuan waktu dan dalam proses reviewnya nanti dapat dipertanggungjawabkan.

Pada dasarnya Demand Chain Management tidak bisa dilepaskan dari eksistensi Supply Chain Management (Mulyono, 2011). Beberapa perusahaan memerlukan satu orang khusus untuk menangani hal ini dan biasanya disebut demand koordinator yang mempunyai tugas utama yaitu melakukan fasilitasi atau koordinasi pembuatan rencana kebutuhan produk atau jasa. Dalam tugasnya harus ada secara formal review bulanan untuk selalu menyesuaikan rencana kebutuhan produk atau jasa yang telah dibuat.

\section{Permasalahan Mitra}

Dalam dunia bisnis yang kompetitif, setiap perusahaan termasuk PT Mitra 10, memerlukan peran strategi bisnis yang tepat, khususnya dalam supply-demand. Oleh karena itu, untuk menghindari kondisi supply-demand yang tidak seimbang, maka perlu dilakukan perencanaan supply-demand yang selalu dimulai dari perencanaan demand. Perencanaan yang mendahulukan demand dalam menentukan jumlah supply akan menghasilkan kondisi supply-demand yang lebih seimbang daripada penyediaan supply tanpa mendahulukan demand.

Perusahaan PT Mitra 10 membutuhkan kompetensi SDM yang unggul, untuk menerapkan demand planning dalam proses bisnisnya. Kompetensi ini diperlukan agar setiap SDM handal dalam menjalankan demand planning. Pelatihan merupakan salah satu cara yang diharapkan dapat meningkatkan kompetensi SDM.

\section{Solusi yang Ditawarkan}

Manajemen logistik merupakan aktivitas yang sangat penting dalam sebuah usaha, karena sangat berpengaruh terhadap besarnya biaya produksi atau operasi yang harus ditanggung. Adanya dinamika permintaan konsumen menuntut pengelolaan logistik untuk menggunakan pendekatan baru yang mampu meningkatkan efisiensi dan kualitas pelayanan. Oleh karena itu, demand planning yang baik dibutuhkan untuk mengelola kegiatan atau proses logistik dalam sebuah perusahaan.

Pada mitra kegiatan pengabdian kepada masyarakat ini yakni PT Mitra 10, pelatihan Demand Planning Management dinilai mampu menjadi solusi pada permasalahan mitra. Pelatihan ini juga dinilai 
mampu memenuhi kebutuhan dari PT Mitra 10 yaitu dengan tujuan membekali peserta mengenai teknik dan metode pengelolaan logistik yang efektif dan terintegrasi, yang meliputi aktivitas pembelian, pergudangan, pengendalian inventori, dan distribusi barang.(Vlckova, 2010)

\section{Tujuan Kegiatan}

Kegiatan pengabdian kepada masyarakat melalui "Pelatihan Demand Planning di PT. Mitra 10" diharapkan menghasilkan outcomes yang tidak hanya bermanfaat bagi Institut Stiami itu sendiri melainkan juga bagi perusahaan dan pelaku logistik.

Hasil pengabdian ini diharapkan dapat membantu memberikan pemahaman pada mitra yakni PT Mitra 10:

1. Melakukan perencanaan supply-demand yang selalu dimulai dari perencanaan demand dalam menentukan jumlah supply akan menghasilkan kondisi supply-demand yang lebih seimbang daripada penyediaan supply tanpa mendahulukan demand.

2. Memahami manajemen untuk mengetahui semua kebutuhan produk atau jasa dari pelanggan. Proses demand management termasuk di dalamnya melakukan aktivitas apa saja yang dibutuhkan agar suatu perusahaan dapat berjalan dengan baik, lebih efektif dan lebih efisien.

\section{B. PELAKSANAAN DAN METODE}

Luaran yang disajikan antara lain meliputi data dan informasi tentang bagaimana perusahaan mengintegrasikan informasi dari dan tentang konsumen, internal dan eksternal perusahaan, ke dalam sistem perencanaan dan pengendalian perusahaan. Manajemen permintaan termasuk aktivitas yang berkisar dari menentukan atau memperkirakan permintaan dari konsumen, dengan mengkonversi pesanan-pesanan spesifik konsumen ke tanggal pengiriman yang dijanjikan, untuk membantu menyeimbangkan permintaan dengan persediaan. Jadi, manajemen permintaan digunakan untuk menggambarkankegiatanperamalan permintaan, perencanaan, dan pemenuhan pesanan.

Pada kegiatan ini, pesertanya adalah para karyawan PT. Mitra 10 Cempaka Putih, Jakarta Pusat.

\section{METODE}

Metode yang digunakan dalam kegiatan ini terdiri atas 3 tahap. Berikut paparan tahapnya:

Tahap Pertama

Tahap pertama merupakan perencanaan kegiatan yang akan dilakukan. Proses perencanaan meliputi identifikasi kebutuhan, identifikasi potensi dan kelemahan yang ada, menentukan jalan keluar dan kegiatan yang akan dilakukan, danmembuat pengorganisasian kegiatan.

Perencanaan disusun oleh Mahasiswa, Tim Pengabdian Masyarakat dan PT. Mitra 10.

\section{Tahap Kedua}

Tahap kedua merupakan pelaksanaan kegiatan.Nara sumber berasal dari Tim Pengabdian kepada Masyarakat yaitu 4 Dosen Tetap Prodi Manajemen Logistik Institut Stiai yang mengikutsertakan 12 Mahasiswa. Peserta adalah karyawan PT. Mitra 10 Cempaka Putih Jakarta Pusat, yang berjumlah 35 orang.

\section{Tahap Ketiga}

Pada tahap ketiga, dilakukan monitoring dan ealuasi kegiatan. Proses ini dilakukan dalam bentuk diskusi tanya jawab naras umber dan peserta.

Pelaksanaan kegiatan dilakukan di PT Mitra 10 dengan metode ceramah (pemberian materi oleh nara sumber) dan diskusi serta tanya jawab (peserta diberikan kesempatan untuk bertanya atas masalah yang terjadi di perusahaan).

\section{HASIL DAN PEMBAHASAN}

\section{Hasil}

Bentuk kegiatan pengabdian kepada masyarakat berjudul: "Demand Planning Management". ini dilaksanakan dengan rincian sebagai berikut: 


\section{Jadwal Kegiatan}

\begin{tabular}{|c|c|c|c|c|}
\hline WAKTU & NAMA KEGIATAN & TEMPAT & $\begin{array}{c}\text { Rician } \\
\text { Kegiatan }\end{array}$ & $\begin{array}{l}\text { PENANGGUNG } \\
\text { JAWAB }\end{array}$ \\
\hline \multicolumn{5}{|c|}{$\begin{array}{c}\text { Tanggal } 15 \text { Mei } 2018 \text { : Pertemuan untuk menyepakati waktu pelaksanaan kegiatan Pengabdian } \\
\text { kepada Masvarakat di Mitra } 10\end{array}$} \\
\hline \multicolumn{5}{|c|}{ Tanggal 4 Juni 2018 : Persiapan Tempat } \\
\hline $15.00-18.00$ & Persiapan & $\begin{array}{l}\text { Kampus Institut } \\
\text { Stiami }\end{array}$ & $\begin{array}{l}\text { Persiapan } \\
\text { Ruangan }\end{array}$ & Tim \\
\hline \multicolumn{5}{|c|}{ Tanggal 5 Juni 2018 : Program Pengabdian Masyarakat } \\
\hline $08.00-09.00$ & $\begin{array}{l}\text { Briefing dan } \\
\text { persiapan kegiatan }\end{array}$ & PT. MITRA 10 & TIM & \multirow{4}{*}{ TIM } \\
\hline $09.00-11.30$ & $\begin{array}{l}\text { Pelatihan Demand } \\
\text { Planning Mangement }\end{array}$ & PT. MITRA 10 & TIM & \\
\hline $11.30-12.00$ & $\begin{array}{l}\text { Diskusi dan Tanya } \\
\text { Jawab }\end{array}$ & PT. MITRA 10 & TIM & \\
\hline $12.00-12.15$ & Penutupan Acara & PT. MITRA 10 & TIM & \\
\hline
\end{tabular}

\section{E. PEMBAHASAN}

Kegiatan ini diharapkan agar mitra kegiatan pengabdian masyarakat ini yakni PT Mitra 10 dapat menerapkan demand planning management. Dari hasil evaluasi sebelum dan sesudah pelatihan melalui tanya jawab, peserta telah dapat memahami perencanaan supply-demand yang selalu dimulai dari perencanaan demand dalam menentukan jumlah supply akan menghasilkan kondisi supply-demand yang lebih seimbang daripada penyediaan supply tanpa mendahulukan demand.

PT Mitra 10 diharapkan dapat mengintegrasikan informasi dari dan tentang konsumen, internal dan eksternal perusahaan, ke dalam sistem perencanaan dan pengendalian perusahaan. Manajemen permintaan termasuk aktivitas yang berkisar dari menentukan atau memperkirakan permintaan dari konsumen, dengan mengkonversi pesanan-pesanan spesifik konsumen ke tanggal pengiriman yang dijanjikan, untuk membantu menyeimbangkan permintaan dengan persediaan. Jadi, manajemen permintaan digunakan untuk menggambarkan kegiatan peramalan permintaan, perencanaan, dan pemenuhan pesanan.

\section{F. PENUTUP}

\section{Simpulan}

Secara umum pelaksanaan Pelatihan Demand Planning Management untuk karyawan PT. Mitra 10 ini berjalan baik, hal ini diperoleh dari hasil evaluasi kepada para peserta pelatihan,

Narasumber yang dihadirkan secara keseluruhan telah memuaskan peserta pelatihan. Evaluasi terhadap relevansi, metode dan media, fasilitas dan konsumsi dinilai peserta telah memuaskan secara keseluruhan atas penyelenggaraan pelatihan ini. Pada proses pembelajaran, sangat menarik sehingga terjadi komunikasi interaktif antara narasumber dengan peserta dimana muncul banyak sekali pertanyaan pertanyaan dari peserta. Hal ini menunjukkan bahwa minat peserta dan materi yang disajikan sangat sesuai dengan kebutuhan di tempat bekerja. Peserta juga memperoleh penjelasan dari narasumber terhadap apa yang menjadi permasalahan di tempat kerja.

\section{Saran}

Kegiatan ini diharapkan dapat terus dilakukan agar peserta mendapatkan pengetahuan dan wawasan baru. Pentingnya kegiatan ini untuk meningkatkan pengetahuan karyawan dan memajukan perusahaan.

\section{G. DAFTAR PUSTAKA}

[1]. Hasibuan, Malayu S.P., (2011). Manajemen Sumber Daya Manusia. Bumi Aksara, Jakarta.

[2]. Heizer, Jay dan Render, Barry. (2016). Manajemen Operasi. Edisi Sebelas.. Jakarta: Salemba Empat

[3]. Kotler, Philip. (2010). Manajemen Pemasaran. Edisi tiga belas Bahasa Indonesia.Jilid 1 dan 2.Jakarta : Erlangga.

[4]. Mulyono, F. (2011). Demand Chain Management : Supply Chain Management + Orientasi Pasar. Jurnal Administrasi Bisnis Unpar, 7(1), 63-76. 
[5]. Ramanda, G. P., \& Vikaliana, R. (2019). Analisis Pemilihan Supplier Alat Tulis Kantor Dengan Metode Analitycal Hierarchy Process Pada PT. Bank XYZ Kantor Pusat. Jurnal Logistik Indonesia, 3(2), 111124. https://doi.org/10.31334/logistik.v3i2.617

[6]. Vlckova, V. (2010). Role of demand planning in business process management. May. https://doi.org/10.3846/bm.2010.151 